\title{
Volatile Substances in Polymer Toys Made from Butadiene and Styrene
}

\author{
Yutaka Abe ${ }^{*}$, Miku Yamaguchi, Motoh Mutsuga, Hiroshi Akiyama, Yoko Kawamura \\ Division of Food Additives, National Institute of Health Sciences, Tokyo, Japan \\ Email: *y-abe@nihs.go.jp
}

Received March 25, 2013; revised April 25, 2013; accepted May 1, 2013

Copyright (C) 2013 Yutaka Abe et al. This is an open access article distributed under the Creative Commons Attribution License, which permits unrestricted use, distribution, and reproduction in any medium, provided the original work is properly cited.

\begin{abstract}
The residual levels and migration behavior of volatile substances were detected using HS-GC/MS for acrylonitrile-butadiene-styrene copolymer (ABS) toys, thermoplastic elastomer toys, and rubber toys made from 1,3-butadiene and styrene found on the Japanese market. The maximum residual level of these volatile substances was $2600 \mu \mathrm{g} / \mathrm{g}$ of styrene in ABS toys. In particular, the levels of known carcinogens 1,3-butadiene, benzene, and acrylonitrile are 5.3, 2.5 and 55 $\mu \mathrm{g} / \mathrm{g}$, which are much lower than the EU limit of $0.1 \%$. Furthermore, some volatile substances migrated from ABS toys into water in amounts of $3-40 \mathrm{ng} / \mathrm{mL}$. Thermoplastic elastomer toys and rubber toys contained these volatile substances at significantly lower levels than ABS toys.
\end{abstract}

Keywords: Volatile Substance; Toy; Acrylonitrile-Butadiene-Styrene Copolymer (ABS); Thermoplastic Elastomer; Rubber

\section{Introduction}

Various plastic materials are used in toys for babies such as teethers, rattles, dolls, toy vehicles, educational toys, and animal toys. Among these toy materials, copolymers made from 1,3-butadiene and styrene as the main monomers are widely used. The acrylonitrile-butadiene-styrene copolymer (ABS) is used as hard materials for the bodies of vehicle toys, the shafts of baby teethers and rattles, and so on. On the other hand, thermoplastic elastomers such as styrene-butadiene-styrene block copolymer (SBS), styrene-ethylene-butadiene-styrene block copolymer (SEBS), and rubbers such as styrene-butadiene rubber (SBR) are used as the soft materials of baby teethers or rattle bodies.

ABS is manufactured from 1,3-butadiene, styrene, and acrylonitrile as the main monomers with some substances. Therefore, unreacted monomers such as 1,3-butadiene [1-3], styrene [4-6], or acrylonitrile [3,4,7] are usually detected in ABS products. Furthermore, other volatile substances such as toluene, ethylbenzene, isopropylbenzene, propylbenzene [4,6], and 4-vinyl-1-cyclohexene [3, 8] derived from the solvent, impurities, or side reactions are also detected. Furthermore, thermoplastic elastomers such as SBS, SEBS, and styrene rubbers such as SBR are also manufactured from 1,3-butadiene and styrene with other substances, and it is unclear whether unreacted mo-

\footnotetext{
"Corresponding author.
}

nomers remain or not.

Among these volatile substances, some have been identified as potentially carcinogenic or toxic substances. The International Agency of Research on Cancer (IARC) has classified 1,3-butadiene as a group 1 carcinogen (carcinogenic to humans); styrene, acrylonitrile, ethylbenzene, and 4-viniyl-1-cyclohexene as group 2B carcinogens (possibly carcinogenic to humans); and toluene as a group 3 carcinogen (not classifiable as to its carcinogenicity to humans) [9]. Meanwhile, the EU has classified 1,3-butadiene as a category $1 \mathrm{~A}$ carcinogen and as a category $1 \mathrm{~B}$ mutagen and has classified acrylonitrile as a category $1 \mathrm{~B}$ carcinogen [10].

Of particular concern is that these substances could be taken orally from chewing toys for babies. Therefore, to ensure the safety of these toys, it is essential to survey the residual levels and migration behavior of the volatile substances in these copolymer toys. However, to the best of our knowledge, only two analyses of the residual levels of these volatile substances in ABS toys have been published $[3,6]$. Moreover, there has been no report of the residual levels of these volatile substances in thermoplastic elastomer toys and rubber toys made from 1,3butadiene and styrene, nor has there been any report on their migration.

In this study, we identified the residual substances and 
determined their residual levels and migration behavior in ABS toys, thermoplastic elastomer toys, and rubber toys on the Japanese market using a headspace gas chromatograph/mass spectrometer (HS-GC/MS).

\section{Experimental}

\subsection{Samples}

Seventy-three toy samples comprising fifty-nine ABS toys, twelve thermoplastic elastomer toys, and two styrene-butadiene rubber toys were collected from the Japanese market in 2011. Two ABS sheets (sheets 1 and 2) were provided for the recovery tests by The Japan Hygienic Olefin and Styrene Plastics Association.

\subsection{Reagents and Standard Solutions}

$N, N$-Dimethylacetamide (DMA, HPLC grade) was purchased from Sigma-Aldrich Japan (Tokyo, Japan). Methanol (HPLC grade) was purchased from Merck (Merck KGaA, Darmstadt, Germany), and $p$-dichlorobenzene
(DCB, special grade, $>98 \%$ ) was purchased from Tokyo Kasei Kogyo Co., Ltd. (Tokyo, Japan).

The standards and internal standards used in this study are shown in Table 1. The mixed volatile substance standard stock solutions were prepared at concentrations of 0.5 - 50,000 $\mu \mathrm{g} / \mathrm{mL}$ in DMA, DCB, and methanol. The mixed internal standard stock solutions were prepared as follows. For the analysis of residual levels of volatile substances in ABS toys, 1,2-butadiene, isobutyronitrile, and $p$-diethylbenzene were mixed in DMA at 100, 10,000, and $1000 \mu \mathrm{g} / \mathrm{mL}$. For the analysis of the residual levels of volatile substances in thermoplastic elastomer toys and rubber toys, 1,2-butadiene, isobutyronitrile, and 1,3,5-trimethylbenzene were mixed in DCB at 100, 10,000, and $1000 \mu \mathrm{g} / \mathrm{mL}$. For the analysis of migration levels of volatile substances, 1,2-butadiene, isobutyronitrile, and $p$-diethylbenzene were mixed in methanol at 100, 500, and $1000 \mu \mathrm{g} / \mathrm{mL}$. All standard stock solutions and internal standard stock solutions were kept in storage bottles with a tightly sealed cap (Kanto Chemical Co., Inc., Tokyo, Japan) and stored at $-20^{\circ} \mathrm{C}$.

Table 1. Standards and internal standards.

\begin{tabular}{|c|c|c|c|c|c|c|}
\hline \multirow{2}{*}{ Chemical name } & \multirow{2}{*}{ CAS No. } & \multirow{2}{*}{$\begin{array}{l}\text { Purity } \\
(\%)\end{array}$} & \multirow{2}{*}{ Supplier ${ }^{* 1}$} & \multirow{2}{*}{$\begin{array}{l}\text { Retention } \\
\text { time (min) }\end{array}$} & \multicolumn{2}{|c|}{ Monitored ion $(m / z)$} \\
\hline & & & & & Quantifying ion & Qualifying ion \\
\hline \multicolumn{7}{|c|}{ Standard } \\
\hline 1,3 -Butadiene ${ }^{* 2}$ & $106-99-0$ & $>95$ & A & 6.1 & 54 & 39,53 \\
\hline Acrylonitrile $^{* 2}$ & $107-13-1$ & $>99.8$ & $\mathrm{~B}$ & 10.7 & 53 & 52 \\
\hline Benzene & $71-43-2$ & $>99$ & $\mathrm{C}$ & 13.2 & 78 & 52 \\
\hline Methylisobutyrate & $547-63-7$ & $>95$ & $\mathrm{D}$ & 13.6 & 43 & 71,41 \\
\hline Methylmethacrylate & $80-62-6$ & $>99.8$ & E & 14.1 & 69 & 41 \\
\hline 1-Octene & $111-66-0$ & $>95$ & $\mathrm{D}$ & 14.9 & 55 & 70 \\
\hline Toluene & $108-88-3$ & $>99.5$ & $\mathrm{~F}$ & 15.0 & 91 & 92 \\
\hline 4-Vinyl-1-cyclohexene & $100-40-3$ & $>95$ & $\mathrm{D}$ & 15.8 & 79 & 54,91 \\
\hline Ethylbenzene & $100-41-4$ & $>99$ & $\mathrm{D}$ & 16.3 & 91 & 106 \\
\hline$p$-Xylene & $106-42-3$ & $>98$ & $\mathrm{D}$ & 16.4 & 91 & 106 \\
\hline Styrene & $100-42-5$ & $>99$ & $\mathrm{D}$ & 16.8 & 104 & 78 \\
\hline Isopropylbenzene & $98-82-8$ & $>98$ & $\mathrm{D}$ & 17.0 & 105 & 120,91 \\
\hline Propylbenzene & $103-65-1$ & $>97$ & $\mathrm{D}$ & 17.4 & 91 & 102,105 \\
\hline$\alpha$-Methylstyrene & 98-83-9 & $>98$ & $\mathrm{D}$ & 17.7 & 118 & 117,91 \\
\hline \multicolumn{7}{|c|}{ Internal standard } \\
\hline 1,2 -Butadiene ${ }^{* 2}$ & $590-19-2$ & $>95$ & A & 7.2 & 54 & 53,39 \\
\hline Isobutyronitrile & $78-67-1$ & $>99$ & $\mathrm{E}$ & 13.1 & 68 & 42 \\
\hline 1,3,5-Trimethylbenzene & $108-67-8$ & $>97$ & E & 17.4 & 105 & 120 \\
\hline$p$-Diethylbenzene & $25340-17-4$ & $>99$ & $\mathrm{D}$ & 18.3 & 105 & 117,120 \\
\hline
\end{tabular}

${ }^{* 1}$ A: Hayashi Pure Chemical Ind., Ltd.; B: AccuStandard; C: Kokusan Chemical Co., Ltd.; D: Wako pure Chemical Industries, Ltd.; E: Tokyo Chemical Industry Co., Ltd.; F: Aldrich Chemical Co., Inc.; ${ }^{* 2}$ Methanol solution $(1000 \mu \mathrm{g} / \mathrm{mL})$. 


\subsection{Headspace (HS)-GC/MS Conditions}

The HS sampler (HP7694, Agilent Technologies, CA, USA) conditions are shown in Table 2, and the GC/MS (6890 GC and 5973 MSD, Agilent Technologies) conditions are as follows. The column was a DB-624 (0.25 $\mathrm{mm}$ i.d. $\times 60 \mathrm{~m}, 1.4 \mu \mathrm{m}$ film thickness [Agilent Technologies]). The oven temperature was initially $40^{\circ} \mathrm{C}$ for 7 min and was then increased at $20^{\circ} \mathrm{C} / \mathrm{min}$ to $250^{\circ} \mathrm{C}$, which was held for $5 \mathrm{~min}$. The injection temperature was $200^{\circ} \mathrm{C}$, and the transfer-line temperature was $250^{\circ} \mathrm{C}$. The helium carrier gas was flowed at $1.2 \mathrm{~mL} / \mathrm{min}$ (constant speed). A split injection mode was used with a ratio of 10:1, and the ion source voltage was $70 \mathrm{eV}$. Finally, a selected ion monitoring (SIM) mode was used, and the monitored ions are given in Table 1.

\subsection{Sample Preparation}

\subsubsection{Determination of Residual Levels of Volatile Substances}

The residual levels of volatile substances in ABS toys were determined using the method reported previously with slight modifications [3]. In brief, each sample $(0.5 \mathrm{~g})$ was cut into small pieces, and $5 \mu \mathrm{L}$ of a mixed internal standard stock solution in DMA and $2.5 \mathrm{~mL}$ of DMA were added in a $20-\mathrm{mL}$ HS vial, which was immediately tightly sealed. The vial was stored overnight at room temperature, and after the sample completely dissolved, the vial was analyzed using HS-GC/MS.

Because the thermoplastic elastomer toys and rubber toys did not dissolve in DMA overnight, these toys were dissolved in DCB. Each sample $(0.1 \mathrm{~g})$ was cut into small pieces, and $5 \mu \mathrm{L}$ of the mixed internal standard stock solution in DCB and $2 \mathrm{~mL}$ of DCB were added in a 20-mL HS vial, which was immediately tightly sealed. Later, the vial was analyzed using HS-GC/MS.

Table 2. HS sampler conditions.

\begin{tabular}{|c|c|c|c|}
\hline \multirow{2}{*}{ Conditions } & \multicolumn{2}{|c|}{ Residual level } & \multirow{2}{*}{ Migration } \\
\hline & ABS & $\mathrm{TE}^{*}$, rubber & \\
\hline Oven temperature & $90^{\circ} \mathrm{C}$ & $140^{\circ} \mathrm{C}$ & $40^{\circ} \mathrm{C}$ \\
\hline Oven heating time & \multicolumn{2}{|c|}{$60 \mathrm{~min}$} & $30 \mathrm{~min}$ \\
\hline Sample loop temperature & $110^{\circ} \mathrm{C}$ & $150^{\circ} \mathrm{C}$ & $80^{\circ} \mathrm{C}$ \\
\hline Transfer-line temperature & \multicolumn{2}{|c|}{$150^{\circ} \mathrm{C}$} & $200^{\circ} \mathrm{C}$ \\
\hline Injection time & \multicolumn{3}{|c|}{$0.5 \mathrm{~min}$} \\
\hline Injection volume & \multicolumn{3}{|c|}{$1.0 \mathrm{~mL}$} \\
\hline Sample loop filling time & \multicolumn{3}{|c|}{$0.1 \mathrm{~min}$} \\
\hline Sample loopequilibration time & \multicolumn{3}{|c|}{$0.1 \mathrm{~min}$} \\
\hline
\end{tabular}

*Thermoplastic elastomer.

\subsubsection{Determination of Amount of Migration of Volatile Substances}

Each test sample was cut to $1 \mathrm{~cm} \times 1 \mathrm{~cm}$ and then placed into a $20-\mathrm{mL}$ HS vial, after which $4 \mathrm{~mL}$ of water and 5 $\mu \mathrm{L}$ of the mixed internal standard stock solution in methanol were added. After all solutions were added, the vial was immediately tightly sealed and then set into the HS sampler. The vial was heated at $40^{\circ} \mathrm{C}$ for $30 \mathrm{~min}$, and then the HS gas was analyzed using GC/MS.

\subsection{Calibration Curve and Limit of Quantification}

To construct the calibration curves for the determination of the residual levels and amounts of migration of volatile substances, standard solutions were prepared as follows.

For the determination of residual levels of volatile substances in ABS toys, 5 - $50 \mu \mathrm{L}$ quantities of the mixed standard stock solutions in DMA were added to $2.5 \mathrm{~mL}$ of DMA in a $20-\mathrm{mL}$ HS vial to obtain the optimal levels for each volatile substance, which ranged from 0.001 to $500 \mu \mathrm{g} / \mathrm{mL}$. Subsequently, $5 \mu \mathrm{L}$ of the mixed internal standard stock solution in DMA was added and the vial was immediately tightly sealed.

For the determination of residual levels of volatile substances in thermoplastic elastomer toys and rubber toys, $4-20 \mu \mathrm{L}$ quantities of the mixed standard stock solutions in DCB were added to $2.0 \mathrm{~mL}$ of DCB in a 20 $\mathrm{mL}$ HS vial to obtain the optimal levels for each volatile substance, which ranged from 0.001 to $5 \mu \mathrm{g} / \mathrm{mL}$. Subsequently, $5 \mu \mathrm{L}$ of the mixed internal standard stock solution in DCB was added, and the vial was immediately tightly sealed.

For the determination of the amount of migration of volatile substances from ABS toys, $4-20 \mu \mathrm{L}$ quantities of the mixed standard stock solutions in methanol were added to $4.0 \mathrm{~mL}$ of water in a $20-\mathrm{mL}$ HS vial to obtain the optimal levels, which ranged from 0.5 to $250 \mathrm{ng} / \mathrm{mL}$. Subsequently, $5 \mu \mathrm{L}$ of the mixed internal standard stock solution in methanol was added, and the vial was immediately tightly sealed.

The prepared standard solutions in the HS vials were analyzed using $\mathrm{HS}-\mathrm{GC} / \mathrm{MS}$, and the calibration curves were constructed by plotting the peak area ratios for 1,3-butadiene versus 1,2-butadiene, for acrylonitrile versus isobutyronitrile, and for other volatile substances versus $p$-diethylbenzene or 1,3,5-trimethylbenzene.

The limit of quantification (LOQ) was defined as a signal-to-noise ratio $(\mathrm{S} / \mathrm{N})$ for the peak intensity of $10 / 1$ for all volatile substances.

\subsection{Recovery Tests}

To evaluate the accuracy of the method, recovery tests 
were performed. The mixed standard stock solutions were spiked into two ABS sheets, two thermoplastic elastomer toys, and two styrene rubber toys. The analytes other than styrene and ethylbenzene were spiked at levels equivalent to 0.5 and $2 \mu \mathrm{g} / \mathrm{g}$, and styrene and ethylbenzene were spiked at levels equivalent to 50 and $200 \mu \mathrm{g} / \mathrm{g}$ in the ABS sheets. All the analytes were spiked at levels equivalent to 0.5 and $2 \mu \mathrm{g} / \mathrm{g}$ in the thermoplastic elastomer and styrene rubber toys.

\section{Results and Discussion}

\subsection{Identification of Residual Volatile Substances}

Among all the analyses of ABS toys, thermoplastic elastomer toys, and rubber toys, 14 peaks were detected using HS-GC/MS analysis in scan mode (Figure 1). Comparison between the mass spectra and retention times corresponding to these 14 peaks and those of the standard substances in the GC/MS database confirmed that the peaks were due to 1,3-butadiene (6.1 min retention time), acrylonitrile (10.7 $\mathrm{min})$, benzene (13.2 $\mathrm{min})$, methylisobutyrate (13.6 $\mathrm{min})$, methylmethacrylate (14.1 $\mathrm{min}), 1$ octene $(14.9 \mathrm{~min})$, toluene $(15.0 \mathrm{~min}), 4$-vinyl-1-cyclohexene (15.8 $\mathrm{min})$, ethylbenzene (16.3 $\mathrm{min})$, xylene (16.4 $\mathrm{min})$, styrene (16.8 $\mathrm{min})$, isopropylbenzene $(17.0 \mathrm{~min})$, propylbenzene $(17.4 \mathrm{~min})$, and $\alpha$-methylstyrene (17.7

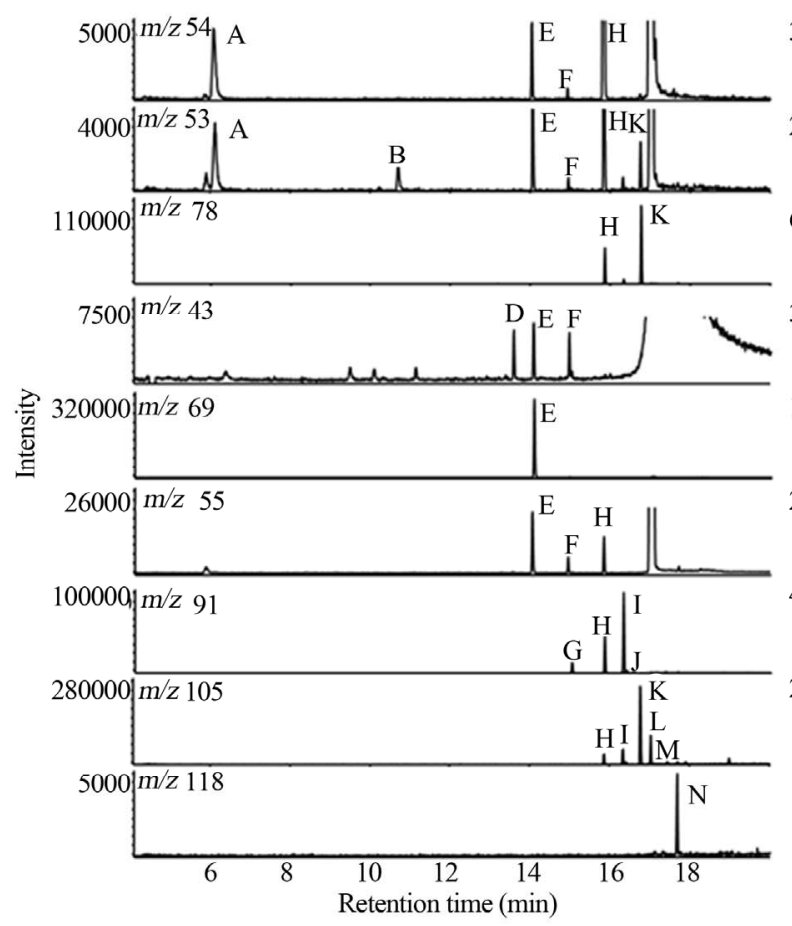

min) (Figure 2).

Among these 14 substances, 1,3-butadiene, acrylonitrile, toluene, 4-vinyl-1-cyclohexene, ethylbenzene, styrene, isopropylbenzene, and propylbenzene were detected in ABS products in previous studies [1-8]. However, this is the first time that benzene, methylisobutyrate, methylmethacrylate, 1-octene, xylene, and $\alpha$-methylstyrene have been detected in ABS products.

In consideration of the process used to manufacture ABS, we speculate that methylmethacrylate and $\alpha$-methylstyrene are derived from the monomer and that the benzene and xylene are from the solvent or impurities in the styrene. In addition, we suppose that methylisobutyrate could be generated by a proton-addition reaction with methylmethacrylate, based on its structure. Finally, although the mechanism for the formation of the 1-octene detected in the ABS products is not clear, we assume that it was generated from the reaction of two molecules of 1,3-buadiene.

\subsection{Determination of Residual Levels of Volatile Substances}

Since $m$-xylene and $p$-xylene were not separated in the GC/MS analysis, we determined the amount of xylene as the sum of both $m$-xylene and $p$-xylene using a $p$-xylene standard. To assess the linearity, calibration curves were

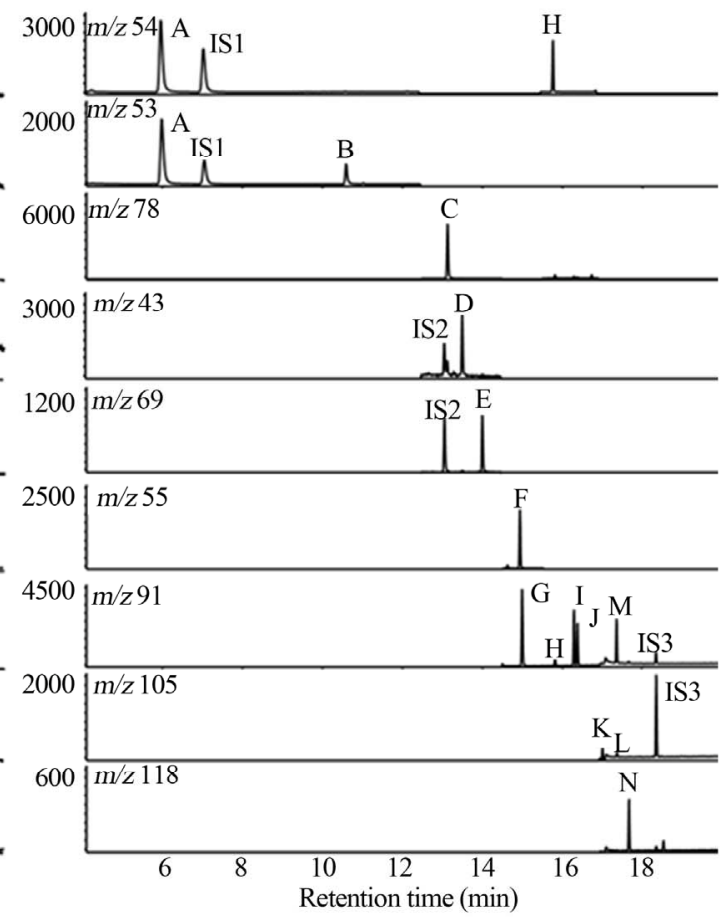

Figure 1. SIM ion chromatograms of ABS toy No. 35 (left) and standard solutions (0.5 $\mu \mathrm{g} / \mathrm{mL})$ (right); A: 1,3-Butadiene; B: Acrylonitrile; C: Benzene; D: Methylisobutyrate; E: Methylmethacrylate; F: 1-Octene; G: Toluene; H: 4-Vinyl-1-cyclohexene; I: Ethylbenzene; J: p-Xylene; K: Styrene; L: Isopropylbenzene; M: Propylbenzene; N: $\alpha$-Methylstyrene; IS1: 1,2-Butadiene; IS2: Isobutyronitrile; IS3: p-Diethylbenzene. 

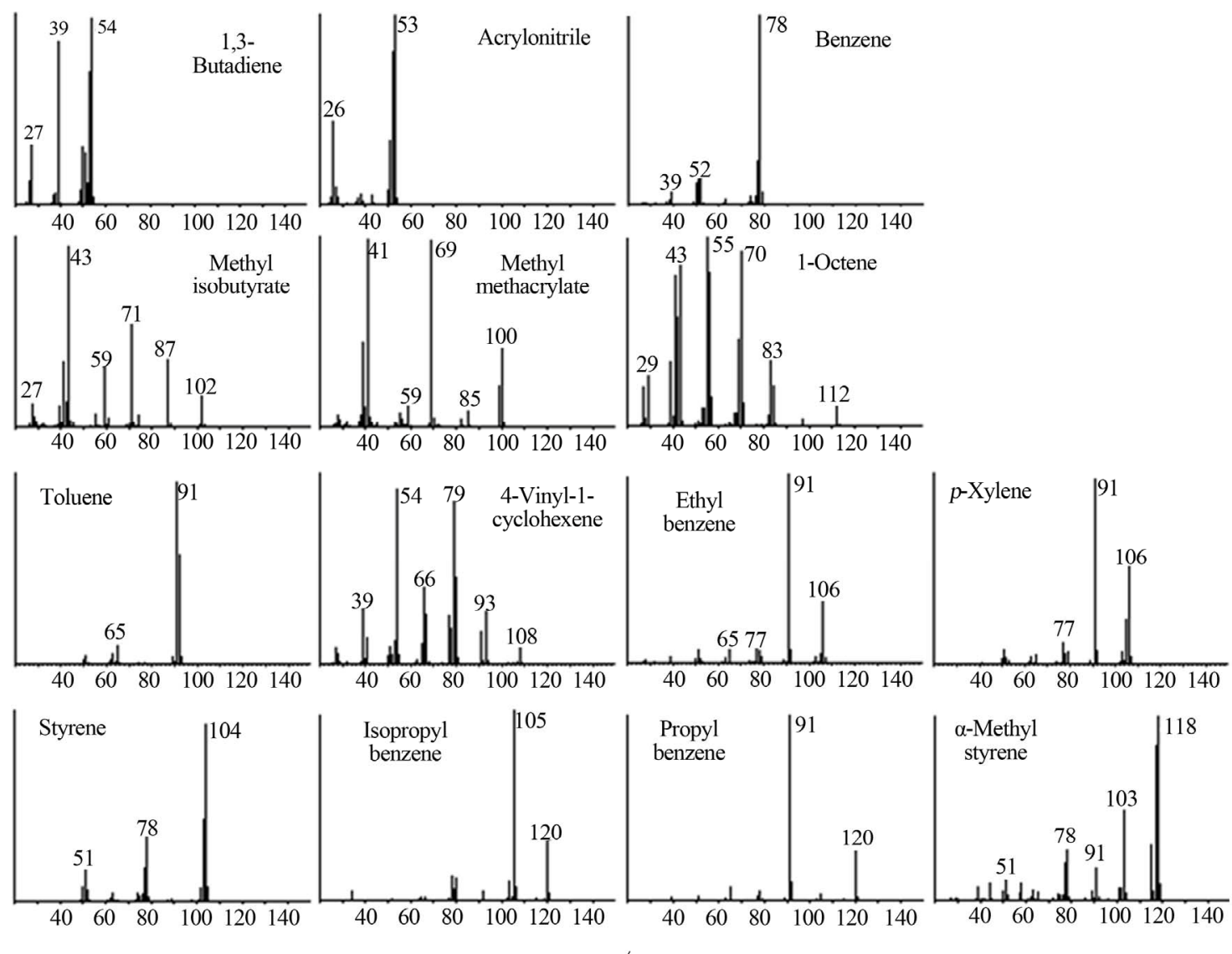

Figure 2. Mass spectra of volatile substances.

constructed using DMA as the solvent for ABS toys and $\mathrm{DCB}$ as the solvent for thermoplastic elastomer and rubber toys. Good linearity was achieved over concentration ranges of $0.005-10 \mu \mathrm{g} / \mathrm{mL}$ for 1,3-butadiene and acrylonitrile, $0.025-500 \mu \mathrm{g} / \mathrm{mL}$ for isopropylbenzene, and $0.01-500 \mu \mathrm{g} / \mathrm{mL}$ for the other volatile substances. The correlation coefficients $R^{2}$ for all volatile substances were $>0.998$. The LOQs for residual volatile substances in ABS toys were estimated to be $0.025 \mu \mathrm{g} / \mathrm{g}$ for $1,3-$ butadiene and acrylonitrile, $0.13 \mu \mathrm{g} / \mathrm{g}$ for isopropylbenzene, and $0.05 \mu \mathrm{g} / \mathrm{g}$ for the other volatile substances. Furthermore, their LOQs in thermoplastic elastomer and rubber toys were estimated to be $0.1 \mu \mathrm{g} / \mathrm{g}$ for 1,3 -butadiene and acrylonitrile, $0.5 \mu \mathrm{g} / \mathrm{g}$ for isopropylbenzene, and $0.2 \mu \mathrm{g} / \mathrm{g}$ for the other volatile substances.

To assess accuracy and precision of the method for determining the residual levels of volatile substances in these toys, recovery tests were performed with three trials (Table 3). The recovery rates of volatile substances in ABS were in the range of $88 \%-105 \%$, and the relative standard deviation (RSD) values were in the range of $0.3 \%-6.5 \%$. Meanwhile, the residual levels of methylmethacrylate and 4-vinyl-1-cyclohexene in ABS sheets were $370 \mu \mathrm{g} / \mathrm{g}$ and $110 \mu \mathrm{g} / \mathrm{g}$, which are much greater than the $0.5 \mu \mathrm{g} / \mathrm{g}$ or $2 \mu \mathrm{g} / \mathrm{g}$ spiking levels. In addition, the standard deviations of the residual levels are larger than the spiking levels described above. These results suggest that it is difficult to assess the recovery of these volatile substances with 0.5 or $2 \mu \mathrm{g} / \mathrm{g}$ spiking levels. However, when volatile substances were spiked at concentrations of 10,50 , and $250 \mu \mathrm{g} / \mathrm{g}$, the recovery rates and RSD values were all in the range of $97 \%-104 \%$ and $1.2 \%$ $4.1 \%$, respectively.

The recovery rates of volatile substances in thermoplastic elastomer toys and rubber toys were in the range of $86 \%-107 \%$, and the RSD values were in the range of $0.6 \%-7.1 \%$. Consequently, acceptable linearity, recovery rates, and RSD values were obtained for all substances, suggesting that these methods are reliable for accurate quantitative determination of the amounts of these volatile substances in ABS toys, thermoplastic elastomer toys, and rubber toys.

The residual levels of volatile substances in ABS toys, are listed in Table 4, which shows that styrene and ethylbenzene have significantly higher residual levels than the other substances. In particular, styrene and ethylbenzene were detected in all ABS toy samples at levels of $6.1-1200$ and $71-2600 \mu \mathrm{g} / \mathrm{g}$, and the substance 
Table 3. Recovery rates of volatile substances.

\begin{tabular}{|c|c|c|c|c|c|c|c|}
\hline Substance & $\begin{array}{c}\text { Spiked levels } \\
(\mu \mathrm{g} / \mathrm{g})\end{array}$ & $\begin{array}{c}\text { ABS } \\
\text { sheet } 1\end{array}$ & $\begin{array}{c}\text { ABS } \\
\text { sheet } 2\end{array}$ & $\mathrm{TE}^{*} 1$ & $\mathrm{TE}^{*} 8$ & Rubber 1 & Rubber 2 \\
\hline \multirow[t]{2}{*}{ 1,3-Butadiene } & 0.5 & $101 \pm 1$ & - & $99 \pm 2$ & $103 \pm 4$ & $101 \pm 4$ & $98 \pm 1$ \\
\hline & 2 & $103 \pm 2$ & - & $99 \pm 2$ & $99 \pm 3$ & $101 \pm 2$ & $101 \pm 1$ \\
\hline \multirow[t]{2}{*}{ Acrylonitrile } & 0.5 & $101 \pm 3$ & - & $103 \pm 2$ & $103 \pm 3$ & $104 \pm 4$ & $102 \pm 1$ \\
\hline & 2 & $104 \pm 2$ & - & $105 \pm 4$ & $107 \pm 3$ & $106 \pm 3$ & $102 \pm 2$ \\
\hline \multirow[t]{2}{*}{ Benzene } & 0.5 & $104 \pm 4$ & $96 \pm 5$ & $97 \pm 4$ & $91 \pm 3$ & $104 \pm 5$ & $95 \pm 3$ \\
\hline & 2 & $101 \pm 2$ & $96 \pm 1$ & $103 \pm 6$ & $99 \pm 1$ & $104 \pm 4$ & $103 \pm 1$ \\
\hline \multirow[t]{2}{*}{ Methylisobutyrate } & 0.5 & $100 \pm 1$ & $101 \pm 2$ & $95 \pm 5$ & $90 \pm 2$ & $103 \pm 3$ & $99 \pm 2$ \\
\hline & 2 & $101 \pm 1$ & $98 \pm 1$ & $98 \pm 7$ & $98 \pm 1$ & $97 \pm 6$ & $101 \pm 1$ \\
\hline \multirow[t]{2}{*}{ Methylmethacrylate } & 0.5 & - & $101 \pm 1$ & $94 \pm 4$ & $93 \pm 1$ & $99 \pm 4$ & $100 \pm 1$ \\
\hline & 2 & - & $100 \pm 1$ & $103 \pm 6$ & $101 \pm 4$ & $101 \pm 6$ & $101 \pm 1$ \\
\hline \multirow[t]{2}{*}{ 1-Octene } & 0.5 & $102 \pm 4$ & $95 \pm 5$ & $101 \pm 5$ & $96 \pm 3$ & $102 \pm 3$ & $98 \pm 2$ \\
\hline & 2 & $99 \pm 2$ & $97 \pm 1$ & $101 \pm 6$ & $102 \pm 2$ & $98 \pm 7$ & $100 \pm 2$ \\
\hline \multirow[t]{2}{*}{ Toluene } & 0.5 & $97 \pm 5$ & $90 \pm 3$ & $102 \pm 3$ & $96 \pm 5$ & $97 \pm 5$ & $101 \pm 2$ \\
\hline & 2 & $104 \pm 1$ & $103 \pm 1$ & $102 \pm 6$ & $98 \pm 1$ & $96 \pm 6$ & $102 \pm 1$ \\
\hline \multirow[t]{2}{*}{ 4-Vinyl-1-cyclohexene } & 0.5 & - & $99 \pm 2$ & $100 \pm 5$ & $97 \pm 2$ & $106 \pm 2$ & $97 \pm 1$ \\
\hline & 2 & - & $102 \pm 4$ & $100 \pm 3$ & $103 \pm 4$ & $98 \pm 6$ & $99 \pm 2$ \\
\hline \multirow[t]{2}{*}{ Ethylbenzene } & 0.5 & $106 \pm 1$ & $94 \pm 3$ & $104 \pm 6$ & $91 \pm 2$ & $103 \pm 5$ & $99 \pm 2$ \\
\hline & 2 & $101 \pm 1$ & $96 \pm 2$ & $97 \pm 6$ & $91 \pm 4$ & $103 \pm 4$ & $101 \pm 1$ \\
\hline \multirow[t]{2}{*}{$p$-Xylene } & 0.5 & $102 \pm 2$ & $98 \pm 1$ & $101 \pm 5$ & $95 \pm 5$ & $104 \pm 5$ & $100 \pm 2$ \\
\hline & 2 & $103 \pm 1$ & $103 \pm 1$ & $96 \pm 6$ & $95 \pm 6$ & $101 \pm 5$ & $90 \pm 6$ \\
\hline \multirow[t]{2}{*}{ Styrene } & 0.5 & $100 \pm 2$ & - & $100 \pm 6$ & $102 \pm 5$ & $97 \pm 3$ & $92 \pm 3$ \\
\hline & 2 & $103 \pm 1$ & - & $99 \pm 5$ & $95 \pm 5$ & $104 \pm 4$ & $100 \pm 2$ \\
\hline \multirow[t]{2}{*}{ Isopropylbenzene } & 0.5 & $96 \pm 6$ & - & $97 \pm 3$ & $102 \pm 1$ & $86 \pm 6$ & $95 \pm 1$ \\
\hline & 2 & $101 \pm 2$ & - & $99 \pm 4$ & $103 \pm 3$ & $100 \pm 6$ & $100 \pm 2$ \\
\hline \multirow[t]{2}{*}{ Propylbenzene } & 0.5 & $99 \pm 6$ & $95 \pm 1$ & $87 \pm 3$ & $99 \pm 2$ & $91 \pm 6$ & $95 \pm 2$ \\
\hline & 2 & $97 \pm 2$ & $100 \pm 3$ & $99 \pm 3$ & $97 \pm 3$ & $98 \pm 3$ & $97 \pm 2$ \\
\hline \multirow[t]{2}{*}{$\alpha$-Methylstyrene } & 0.5 & $103 \pm 5$ & - & $101 \pm 4$ & $100 \pm 5$ & $95 \pm 4$ & $98 \pm 4$ \\
\hline & 2 & $101 \pm 3$ & - & $104 \pm 5$ & $93 \pm 6$ & $97 \pm 6$ & $99 \pm 1$ \\
\hline
\end{tabular}

Mean \pm RSD of three trials (\%); Ethylbenzene and styrene were spiked at 10 and $50 \mu \mathrm{g} / \mathrm{g}$ in ABS sheet 1 and $2 ;^{*}$ Thermoplastic elastomer.

with the next highest residual levels was toluene, which was detected in all samples at $0.38-590 \mu \mathrm{g} / \mathrm{g}$. The residual levels of 4-vinyl-1-cyclohexene, isopropylbenzene, and methylmethacrylate were over $100 \mu \mathrm{g} / \mathrm{g}$ in some samples, whereas those of most other volatile substances were below $50 \mu \mathrm{g} / \mathrm{g}$.

Ohno et al. reported that 1,3-butadiene, acrylonitrile, 4-vinyl-1-cyclohexene, ethylbenzene, toluene, styrene, isopropylbenzene, and propylbenzene were detected in
ABS toys on Japanese market in 2004-2006 at levels of 0.06 - 1.03, 5.4 - 43.6, 1.5 - 295, 50 - 310, 10 - 2520, 160 - 3570, $10-230$, and $10-120 \mu \mathrm{g} / \mathrm{g}$, respectively $[3,6]$. The residual amount of 1,3-butadiene in our present result is slightly greater than that obtained in 2004-2006, but the residual amount of styrene is slightly lower. The residual levels of acrylonitrile, 4-vinyl-1-cyclohexene, ethylbenzene, toluene, isopropylbenzene, and propylbenzene are identical to those obtained in 2004-2006. 
Table 4. Number of detected samples and residual levels of volatile substances in ABS toys.

\begin{tabular}{|c|c|c|c|c|c|c|}
\hline \multirow{2}{*}{ Volatile substance } & \multirow{2}{*}{$\begin{array}{l}\text { Number of } \\
\text { detected } \\
\text { samples }\end{array}$} & \multirow{2}{*}{$\begin{array}{c}\text { Percent of } \\
\text { detected } \\
\text { samples (\%) }\end{array}$} & \multicolumn{4}{|c|}{ Residual level $(\mu \mathrm{g} / \mathrm{g})$} \\
\hline & & & Min. & Max. & Mean & LOQ \\
\hline 1,3-Butadiene & 52 & 88 & 0.04 & 5.3 & 0.78 & 0.025 \\
\hline Acrylonitrile & 56 & 95 & 0.42 & 55 & 14 & 0.025 \\
\hline Benzene & 36 & 61 & 0.05 & 2.5 & 0.47 & 0.05 \\
\hline Methylisobutyrate & 12 & 20 & 0.27 & 11 & 3.8 & 0.05 \\
\hline Methylmethacrylate & 37 & 63 & 1.8 & 530 & 101 & 0.05 \\
\hline 1-Octene & 15 & 25 & 0.06 & 5.3 & 1.7 & 0.05 \\
\hline Toluene & 59 & 100 & 0.38 & 590 & 21 & 0.05 \\
\hline 4-Vinyl-1-cyclohexene & 57 & 97 & 0.42 & 280 & 46 & 0.05 \\
\hline Ethylbenzene & 59 & 100 & 6.1 & 1200 & 117 & 0.05 \\
\hline Xylene & 56 & 95 & 0.20 & 84 & 22 & 0.05 \\
\hline Styrene & 59 & 100 & 71 & 2600 & 928 & 0.05 \\
\hline Isopropylbenzene & 56 & 95 & 1.9 & 130 & 24 & 0.13 \\
\hline Propylbenzene & 59 & 100 & 0.17 & 40 & 7.6 & 0.05 \\
\hline$\alpha$-Methylstyrene & 58 & 98 & 0.36 & 99 & 26 & 0.05 \\
\hline \multicolumn{3}{|c|}{ Total residual levels of five volatile substances ${ }^{*}$} & 100 & 2900 & 1100 & \\
\hline
\end{tabular}

*Five volatile substances: toluene, ethylbenzene, styrene, isopropylbenzene and propylbenzene.

The total residual levels of the five volatile substances regulated in Japan, toluene, ethylbenzene, styrene, isopropylbenzene, and propylbenzene, were $330-4520 \mu \mathrm{g} / \mathrm{g}$ (average $2610 \mu \mathrm{g} / \mathrm{g}$ ) in 2004-2006 [6], while in this study they were $100-2900 \mu \mathrm{g} / \mathrm{g}$ (average $1100 \mu \mathrm{g} / \mathrm{g}$ ), which is a statistically significant difference. Thus, the residual levels of volatile substances in the recently produced commercially available ABS toys are lower than before.

The residual levels of volatile substances in thermoplastic elastomer toys and rubber toys are shown in Table 5, which represents the first reported data for these types of toys. In thermoplastic elastomer toys, xylene, styrene, ethylbenzene, toluene, $\alpha$-methylstyrene, acrylonitrile, and 1-octene were detected at levels of $0.2-1.4$, $0.2-0.5,0.2-0.4,0.3,0.3,0.2$, and $0.2 \mu \mathrm{g} / \mathrm{g}$, respectively. In styrene rubber toys, only xylene was detected at level of $1.2 \mu \mathrm{g} / \mathrm{g}$ from one sample. The residual levels of volatile substances detected in thermoplastic elastomer toys and rubber toys were much lower than those detected in ABS toys.

\subsection{Determination of Amount of Migration of Volatile Substances from ABS Toys}

To prevent these volatile substances from volatilizing from the solution after migration, the migration test was performed in a hermetically sealed HS vial, and the vial was analyzed using HS-GC/MS. To assess the linearity, calibration curves were constructed using water as the solvent. Good linearity was achieved over the concentration range of $3-250 \mathrm{ng} / \mathrm{mL}$ for acrylonitrile and methylmethacrylate and over the concentration range of 1 $250 \mathrm{ng} / \mathrm{mL}$ for other volatile substances. The correlation coefficients $R^{2}$ for all volatile substances were $>0.997$. The LOQs for the amounts of volatile substances migrated from ABS toys were estimated to be $3 \mathrm{ng} / \mathrm{mL}$ for acrylonitrile and methylmethacrylate and $1 \mathrm{ng} / \mathrm{mL}$ for other volatile substances.

The migration tests were conducted on 10 ABS samples in which the residual levels of volatile substances were especially high. The amounts of volatile substances that migrated from these ABS samples into water at $40^{\circ} \mathrm{C}$ for $30 \mathrm{~min}$ are shown in Table 6. The styrene, ethylbenzene, methylmethacrylate, and acrylonitrile migrated in amounts of $7-40 \mathrm{ng} / \mathrm{mL}$ from 9 samples, $3-26 \mathrm{ng} / \mathrm{mL}$ from 4 samples, $8 \mathrm{ng} / \mathrm{mL}$ from 2 samples, and $3 \mathrm{ng} / \mathrm{mL}$ from 1 sample, respectively. It has been suggested that volatile substances can easily migrate from cut edges of ABS samples [11], which might explain these detected volatile substances. It should also be noted that these detected volatile substances might have migrated into the water via methanol from the samples, since trace levels of the methanol used as a solvent for the internal 
Table 5. Number of detected samples and residual levels of volatile substances in thermoplastic elastomer and rubber toys.

\begin{tabular}{|c|c|c|c|c|c|c|}
\hline \multirow{2}{*}{ Volatile substance } & \multicolumn{2}{|c|}{ Number of detected samples } & \multicolumn{4}{|c|}{ Residual level $(\mu \mathrm{g} / \mathrm{g})$} \\
\hline & $\mathrm{TE}^{*}$ & Rubber & Min. & Max. & Mean & LOQ \\
\hline 1,3-Butadiene & 0 & 0 & - & - & - & 0.1 \\
\hline Acrylonitrile & 1 & 0 & & 0.2 & & 0.1 \\
\hline Benzene & 0 & 0 & - & - & - & 0.2 \\
\hline Methylisobutyrate & 0 & 0 & - & - & - & 0.2 \\
\hline Methylmethacrylate & 0 & 0 & - & - & - & 0.2 \\
\hline 1-Octene & 1 & 0 & & 0.2 & - & 0.2 \\
\hline Toluene & 1 & 0 & & 0.3 & & 0.2 \\
\hline 4-Vinyl-1-cyclohexene & 0 & 0 & - & - & - & 0.2 \\
\hline Ethylbenzene & 3 & 0 & 0.2 & 0.4 & 0.3 & 0.2 \\
\hline Xylene & 5 & 1 & 0.2 & 1.4 & 0.7 & 0.2 \\
\hline Styrene & 5 & 0 & 0.2 & 0.5 & 0.3 & 0.2 \\
\hline Isopropylbenzene & 0 & 0 & - & - & - & 0.5 \\
\hline Propylbenzene & 0 & 0 & - & - & - & 0.2 \\
\hline$\alpha$-Methylstyrene & 1 & 0 & & 0.3 & & 0.2 \\
\hline
\end{tabular}

${ }^{*}$ Thermoplastic elastomer.

Table 6. Migration levels of volatile substances from ABS toys.

\begin{tabular}{|c|c|c|c|c|c|c|c|c|}
\hline \multirow{2}{*}{ Sample } & \multicolumn{4}{|c|}{ Residual level $(\mu \mathrm{g} / \mathrm{g})$} & \multicolumn{4}{|c|}{ Amount migrated $(\mathrm{ng} / \mathrm{mL})$} \\
\hline & $\mathrm{AN}$ & MMA & EB & ST & $\mathrm{AN}$ & MMA & EB & ST \\
\hline ABS5 & 16 & NQ & 160 & 2600 & NQ & NQ & NQ & 15 \\
\hline ABS6 & 22 & 34 & 91 & 1400 & NQ & NQ & NQ & 16 \\
\hline ABS9 & 1.2 & 250 & 1200 & 520 & NQ & 8 & 26 & 12 \\
\hline ABS16 & 55 & NQ & 180 & 2100 & 3 & NQ & NQ & 23 \\
\hline ABS26 & 4.2 & 460 & 58 & 510 & NQ & 8 & NQ & 6 \\
\hline ABS29 & 13 & NQ & 340 & 1100 & NQ & NQ & 12 & 38 \\
\hline ABS38 & 8.2 & 6.7 & 65 & 810 & NQ & NQ & 3 & 40 \\
\hline ABS41 & 20 & NQ & 62 & 1000 & NQ & NQ & 3 & 40 \\
\hline ABS44 & NQ & 78 & 6.1 & 71 & NQ & NQ & NQ & 7 \\
\hline ABS45 & 0.42 & 130 & 89 & 180 & NQ & NQ & NQ & NQ \\
\hline LOQ & 0.025 & 0.05 & 0.05 & 0.05 & 3 & 3 & 1 & 1 \\
\hline
\end{tabular}

Mean of two trials, NQ = not quantified (under the LOQ).

standards were present in the migration test solvent. Thus, the actual amounts of these detected volatile substances that migrate into children's saliva are considered to be lower than those reported in this study.
The other volatile substances detected in the toys, 1,3butadiene, benzene, methylisobutyrate, 1-octene, toluene, 4-vinyl-1-cyclohexene, xylene, isopropylbenzene, propylbenzene, and $\alpha$-methylstyrene, were not found to have 
migrated from any of the 10 samples.

\section{Conclusions}

The residual levels of volatile substances in 59 ABS toys, 12 thermoplastic elastomer toys, and 2 styrene rubber toys on the Japanese market were determined using HSGC/MS, and 1,3-butadiene, acrylonitrile, benzene, methylisobutyrate, methylmethacrylate, 1-octene, toluene, 4-vinyl-1-cyclohexene, ethylbenzene, xylene, styrene, isopropylbenzene, propylbenzene, and $\alpha$-methylstyrene were detected.

In the EU, chemical substances that are classified as category $1 \mathrm{~A}, 1 \mathrm{~B}$, or 2 carcinogens, mutagens, or reprotoxic substances (CMR substances) under Regulation (EC) No. 1272/2008 cannot be used in toys, and the limit for residual levels is $0.1 \%$. Among the volatile substances detected in this study, 1,3-butadiene, acrylonitrile, and benzene are specified as CMR substances, 1,3-butadiene and benzene are classified as category $1 \mathrm{~A}$ carcinogens and category $1 \mathrm{~B}$ mutagens, and acrylonitrile is classified as a category $1 \mathrm{~B}$ carcinogen. The residual levels of these volatile substances in the samples tested in this study are much lower than the EU limit of $0.1 \%$. On the other hand, the residual levels of styrene and ethylbenzene were over $1000 \mu \mathrm{g} / \mathrm{g}$ in some ABS samples.

Moreover, the amounts of migration of volatile substances from 10 ABS samples with especially high residual levels were also determined. However the amounts of all volatile substances that migrated from these samples into water were under $40 \mathrm{ng} / \mathrm{mL}$. They might be mainly due to migration from the cut edges of the samples, and the actual amounts of these volatile substances that migrate into children's saliva are considered to be lower than those reported in this study.

However, measuring the actual levels of children's exposure to these volatile substances from toys is difficult, and thus continuous investigation like that performed here is important for ensuring toys' safety. In addition, determination of the residual levels of volatile substances in other polymer toys remains necessary.

\section{Acknowledgements}

We are grateful to Dr. Hiroyuki Ohno (Nagoya City Public Health Research Institute) for helpful advice, and The Japan Toy Association and Japan Hygienic Olefin and Styrene Plastics Association for providing samples.

This study was supported by grants from the Ministry of Health, Labour and Welfare, Japan.

\section{REFERENCES}

[1] S. Tan and T. Okada, "Determination of Residual 1,3-Butadiene in Synthetic Resins Containing Butadiene," Journal of the Food Hygienic Society of Japan, Vol. 22, No. 2, 1981, pp. 150-154. doi:10.3358/shokueishi.22.150

[2] J. R. Startin and J. Gilbert, "Single Ion Monitoring of Butadiene in Plastics and Foods by Coupled Mass Spectrometry-Automatic Headspace Gas Chromatography," Journal of Chromatography A, Vol. 294, 1984, pp. 427 430. doi:10.1016/S0021-9673(01)96157-6

[3] H. Ohno and Y. Kawamura, "Analysis of Acrylonitrile, 1,3-Butadiene, and Related Compounds in AcrylonitrileButadiene-Styrene Copolymers for Kitchen Utensils and Children's Toys by Headspace Gas Chromatography/ Mass Spectrometry," Journal of AOAC International, Vol. 93, No. 6, 2010, pp. 1965-1971.

[4] R. Yoshida, Y. Watanabe, K. Sato and F. Endo, "Survey of Residual Acrylonitrile Monomer in AS and ABS Resin Food Containers," Annual Report of the Tokyo Metropolitan Research Laboratory of Public Health, Vol. 30, No. 1, 1979, pp. 163-166.

[5] H. Ohno, M. Suzuki, T. Aoyama and K. Mizutani, "Survey of Residual Substances in Polystyrene and Styrene Copolymer Products for Kitchen Utensils and Food Containers," Annual Report of Nagoya City Public Health Research Institute, Vol. 48, 2002, pp. 61-65.

[6] H. Ohno, M. Suzuki and M. Nakajima, "Survey of Residual Volatile Substances in Acrylonitrile-ButadieneStyrene Copolymer and Polystyrene Toys," Annual Report of Nagoya City Public Health Research Institute, Vol. 54, 2008, pp. 58-61.

[7] J. Gilbert and J. R. Startin, "Determination of Acrylonitrile Monomer in Food Packaging Materials and in Foods," Food Chemistry, Vol. 9, No. 4, 1982, pp. 243252. doi:10.1016/0308-8146(82)90075-9

[8] S. Tan, T. Tatsuno and T. Okada, "Selected-Ion Monitoring of 4-Vinyl-1-cyclohexene in Acrylonitrile-ButadieneStyrene Polymer Products and Food Simulants," Journal of Chromatography A, Vol. 482, No. 1, 1989, pp. 246251. doi:10.1016/S0021-9673(01)93226-1

[9] International Agency for Research on Cancer, "IARC Monographs on the Evaluation of Carcinogenic Risks to Humans," 2012.

[10] "Directive 2009/48/EC of the European Parliament and of the Council of 18 June 2009 on the Safety of Toys," Official Journal of the European Union, L170/1, 2009, pp. 1-37.

[11] European Standard EN 13130-1:2004, "Materials and Articles in Contact with Food Stuffs," 2004, pp. 1-62. 